\title{
First report of the old world genus Pelecystola in North America, with description of a new species (Lepidoptera,Tineidae)
}

\author{
Steven R. Davis ${ }^{1, \dagger}$, Donald R. Davis ${ }^{2, \ddagger}$ \\ I Division of Entomology, Natural History Museum, and Department of Ecology \& Evolutionary Biology, \\ University of Kansas, Lawrence, Kansas 2 Department of Entomology, National Museum of Natural History, \\ Smithsonian Institution, Washington, D.C., U.S.A. \\ † urn:lsid:zoobank.org:author:A6D33B50-CDD6-460E-838E-AC7BF43888A2 \\ †urn:lsid:zoobank.org:author:FC851800-FEE2-46CF-8C55-B4A2D5EEFF66 \\ Corresponding author: Donald R. Davis (davisd@si.edu) \\ Academic editor: Christian Schmidt | Received 09 May 2009 | Accepted 15 September 2009 | Published 23 October 2009 \\ urn:lsid:zoobank.org:pub:35AED996-08D5-4181-90C3-897BA868EEA1 \\ Citation: Davis SR, Davis DR (2009) First report of the old world genus Pelecystola in North America, with description \\ of a new species (Lepidoptera, Tineidae). ZooKeys 25: 69-78. doi: 10.3897/zookeys.25.197

\begin{abstract}
The tineid genus Pelecystola, which was previously represented by six widely scattered species known only from the Palearctic, Indomalayan, and Ethiopian regions, is reported for the first time from the western hemisphere. The new species, Pelecystola nearctica, has been found to occur rather commonly over much of eastern North America from Quebec, Canada, south in the United States to Florida and west to Arkansas. The genus Pelecystola is partially characterized by the development of a pedunculate pectinifer which arises from the extreme base of the male valva, a character also shared by the austral South American genus Falsivalva. Although the genus has sometimes been referred to the Scardiinae, the subfamily affinities of Pelecystola as well as the larval biology remain unresolved.
\end{abstract}

\section{Keywords}

Biogeography, Falsivalva, genital morphology, pectinifer, Scardiinae 


\section{Introduction}

Prior to this report, the tineid genus Pelecystola was known only from the Palearctic, Indomalayan, and Ethiopian regions where six species occur widely scattered from Europe (P. fraudulentella Zeller), Africa ( $P$. decorata Meyrick, $P$. melanchares (Meyrick), P. polysticha (Meyrick), and P. tephrinitis (Meyrick)), eastward to India, Indonesia, and Japan,(P. strigosa (Moore) (= P. hierophanta (Meyrick), P. maculella (Matsumura)) (Robinson and Tuck 1996, Robinson 2008, Sakai 2002). Although P. nearctica is now relatively common and widespread over much of the eastern United States, the first recorded collection of this rather easily recognized moth dates back to only 1961 from Florida. Ten years later it was collected in Delaware. Because of its relatively recent history and its distribution along the Atlantic seaboard, $P$. nearctica was first suspected of being introduced from the Old World. Comparisons of the male genitalia of all six previously named species, however, have confirmed its status as previously unnamed. The larval biology of Pelecystola is unknown.

\section{Pelecystola Meyrick}

Pelecystola Meyrick, 1920: 103. Type species: Pelecystola decorata Meyrick, 1920. Zularcha Meyrick, 1937: 75. Type species: Zularcha melanochares Meyrick, 1937. Neurozestis Meyrick, 1938: 25. Type species: Neurozestis polysticha Meyrick, 1938.

Adult. Moderately large-sized tineid moths with forewing lengths $5.4-10 \mathrm{~mm}$.

Head (Figs 2-3): Vestiture rough; vertex and frons densely covered with erect, piliform scales with acute apices. Antenna simple, ciliate, bipectinate in P. strigosa Moore, 0.5$0.6 \times$ length of forewing; scape slightly flattened, smoothly scaled, with pecten consisting of 6-25 bristles; flagellum with a single row of moderately broad scales dorsally on each segment. Eye moderately developed; interocular index -0.6 ; frons broad. Ocellus absent. Pilifer undeveloped. Mandible vestigial. Galea reduced, 0.9-1.0x length of maxillary palpus. Maxillary palpus elongate, 5 -segmented, with apical segment minute; length ratio of segments from base: 1.0: 0.9: 1.0: 3.75: 0.3-0.4. Labial palpus well developed; length ratio of segments from base: 1.0:3.2:1.7; vestiture relatively smooth dorsally, moderately rough ventrally with $2-8$ dark, elongate bristles arising mostly laterally along segment 2 .

Thorax: Forewing (Fig. 4) moderately slender, W/L ratio -0.35 , apex moderately rounded. Venation well preserved with most veins distinct. Forewing venation variable, usually with all 5 branches of R present and separate; Rs 2 absent in $P$. decorata, Rs 3 and 4 stalked in $P$. decorata and $P$. strigosa; accessory cell distinct, mostly closed; M1-3 all separate; $\mathrm{CuA} 1-2$ well preserved; $\mathrm{CuP}$ indistinct for most its length; $\mathrm{A} 1$ and 2 with basal fork, then fused nearly $2 / 3$ their length; male retinaculum an elongate, basal, ventral fold, curled distally; female retinaculum consisting of a loose concentration of elongate hairs from ventral base of Sc. Hindwing W/L ratio - 0.4; M1-3 all separate; CuA1 and 2 well developed; $1 \mathrm{~A}+2 \mathrm{~A}$ well preserved; $3 \mathrm{~A}$ distinct; frenula a single stout bristle in male, 2 
tightly appressed bristles in female. Legs with tibial spur pattern of 0-2-4; epiphysis well developed, more than half the length of foretibia; tibial spurs of unequal lengths.

Abdomen: Without specialized structures; S2 apodemes slender, nearly straight, elongate, $-0.5-0.7 \times$ length of S2. Male coremata and female corethrogyne absent.

Male genitalia: Uncus usually deeply bilobed, superficially bilobed in some African species. Gnathos absent. Vinculum and tegumen a relatively broad ring, with lateral fusion indistinct; saccus usually short, more elongate in $P$. polysticha. Valva deeply divided into two (cucullar and saccular) lobes; an elongate, slender stalk arising from extreme base of costal margin of valva which enlarges apically to form a spatulate tip bearing a pectinifer consisting of a single row of minute spines. Juxta absent. Aedoeagus usually a slender, moderate to elongate cylinder; cornuti absent.

Female genitalia: Ovipositor elongate, telescoping. Posterior apophysis $\sim 1.7-1.9 \times$ length of anterior pair. Ventral pseudapophysis absent. Ostium bursae a sclerotized ring located near anterior margin of sternum 8. Ductus bursae slender, exceeding length of anterior apophysis, with lightly sclerotized antrum. Corpus bursae relatively large, $-0.5-0.7 \times$ the length of ductus bursae, mostly membranous, with a V-shaped signum consisting of a pair of slender arms converging and partially fused posteriorly.

Discussion. The generic and subfamily relationships of this aberrant genus are uncertain. Gozmány and Vári (1973) suggested that Pelecystola could be included within the Scardiinae based on superficial characters, a conclusion also followed by Sakai (2002). A specimen of the new species, P. nearctica, along with numerous other genera of Tineidae, have been sequenced for five nuclear genes as part of the Lepidoptera Tree of Life project, supported by the U.S. National Science Foundation. Results from these sequences have yet to be analyzed, but it is hoped that they might provide better resolution of the subfamily relationships of Pelecystola. As pointed out by Gozmány and Vári (1973) and others, Pelecystola is largely characterized by the peculiar pedunculate pectinifers arising on long stalks from the costal base of the male valvae. As discussed by S. and D. Davis (2009), few tineid genera are known to possess a pectinifer on the valva. Of those that do, the slightly more complex pectinifers of the South American genus Falsivalva resemble those of Pelecystola the most in arising on slender stalks from the extreme base of the valvae. However, the two genera share little else in common. The male genitalia of Falsivalva differ from that of Pelecystola and all other Tineidae in the extreme development of a greatly lengthened and almost completely divided tegumen (Davis and Davis 2009). In addition, the female genitalia of Falsivalva lack signa.

\section{Pelecystola nearctica S. Davis \& D. Davis, sp. n.}

urn:lsid:zoobank.org:act:618FD1B6-A400-4D52-A4C4-6D77EC524DB7

Figs 1-12

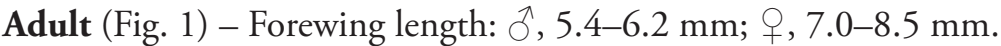

Head: Mostly cream, with caudal most scales of occiput fuscous. Antenna dark brown to fuscous dorsally and ventrally; scape cream ventrally. Maxillary palpus mostly 

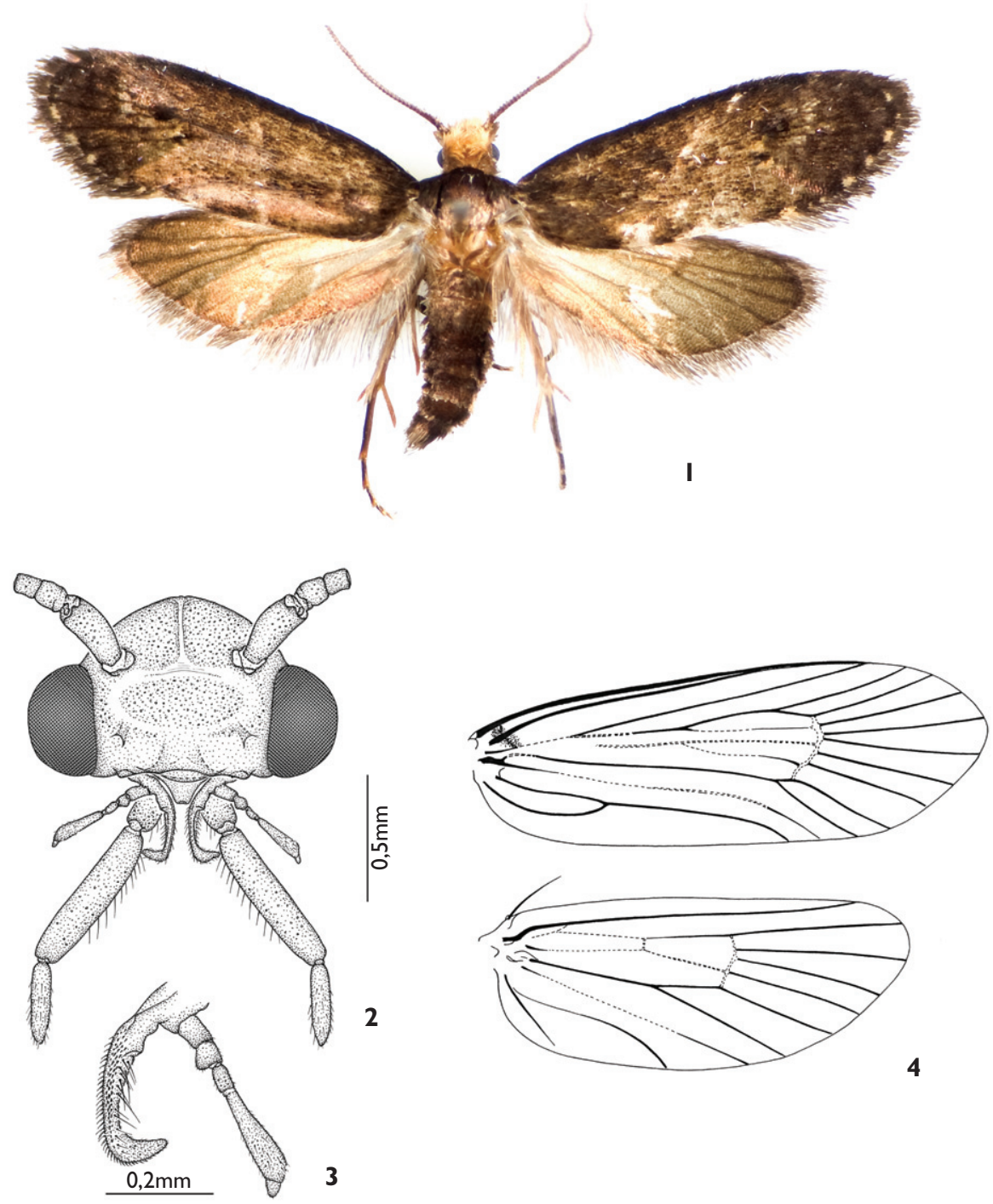

Figures I-4. Pelecystola nearctica sp. n. I Holotype $\widehat{\jmath}$, forewing length $7 \mathrm{~mm}$. 2 Head, frontal view 3 Left maxilla 4 Wing venation.

cream basally, grayish-brown over segments 4-5. Labial palpus cream mesally, dark grayish brown laterally, with $-2-5$ long, fuscous bristles arising dorsolaterally on segment 2 .

Thorax: Pro- and mesonota fuscous; tegulae fuscous, sometimes with a few grayish white scales caudally; metanotum partially naked, light grayish-brown to brown; venter of thorax mostly white, suffused with gray. Forewing predominantly fuscous, lightly marked with several small cream spots as follows: a very small spot at basal $1 / 3$ of $\mathrm{Cu}-\mathrm{CuP} ; 1-2$ spots at apex of discal cell and 3-5 small spots scattered beyond apex of cell between bases of Rs1-4; a variable series of 6-9 small subterminal spots between 

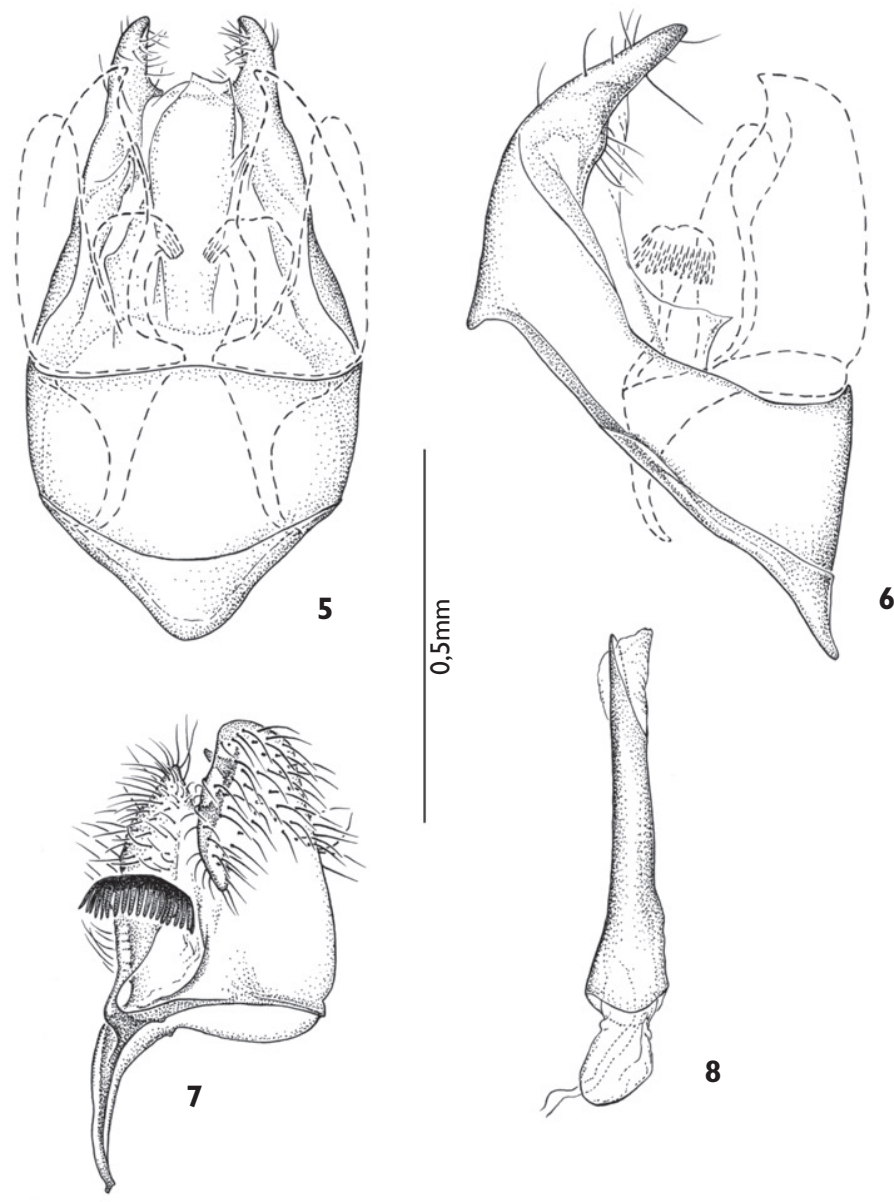

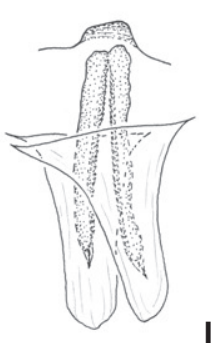

$0,1 \mathrm{~mm}$

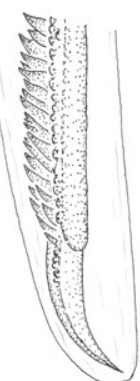

| |

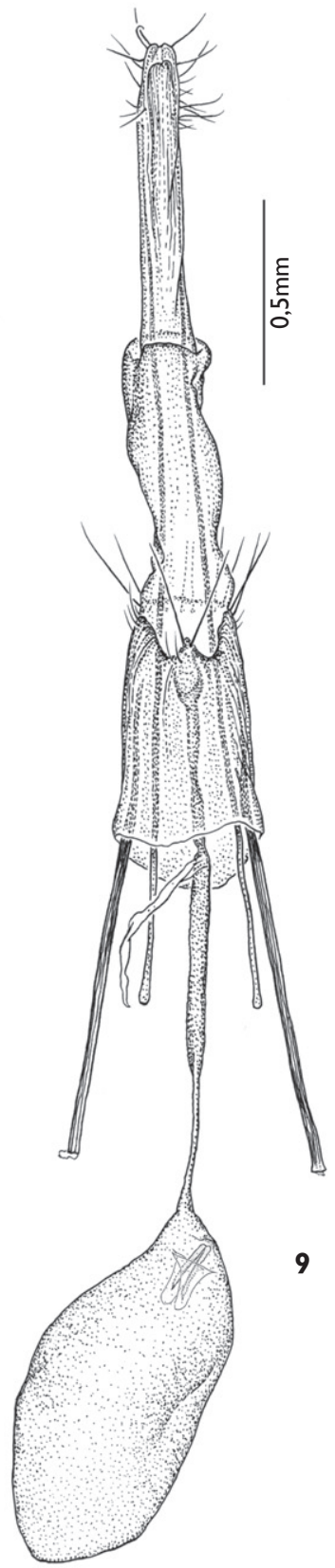

Figures 5-II. Pelecystola nearctica sp. n. 5-8 Male genitalia: 5 Genital capsule, ventral view 6 Lateral view of fig. 57 Valva, mesal-lateral view 8 Aedoeagus 9-I I Female genitalia: 9 Ventral view (scale $0.5 \mathrm{~mm}$ ) 10 Detail of signum in fig. 9 I I Detail of serrated edge of one of the paired arms of signum in fig. 10. 
apices of Rs1 and $\mathrm{CuA} 2$; terminal fringe dark gray. Hindwing mostly dark grayish brown; fringe mostly light grayish brown, with dark brown basal band. Fore- and midlegs mostly fuscous dorsally, light brown to cream ventrally; hindlegs dark brown to steely-gray dorsally, light brown to cream ventrally; coxae of mid- and hindlegs mostly white; apices of all tibiae and tarsomeres cream to light brown.

Abdomen: Fuscous to steely-gray dorsally and laterally; light brown to cream ventrally.

Male genitalia (Figs 5-8): Uncus deeply lobed, with lobes widely separated a distance slightly greater than length of lobes. Tegumen and vinculum forming a moderately broad, mostly fused ring; saccus moderately developed, broadly rounded. Valva divided approximately half its length to form subacute cucullar lobe and broader, more rounded saccular lobe; saccular lobe with a small subapical spine; a pedunculate pectinifer $\sim$ half the length of valva arising on a slender stalk from costal margin at extreme base of valva; stalk gradually enlarging to a relatively broad apex bearing 18-20 reflexed spines. Aedoeagus a slender tube $-0.6 \times$ length of genital capsule, with base slightly broader.

Female genitalia (Figs 9-11): Posterior apophysis elongate, $\sim 1.8 \times$ length of anterior apohysis. Ductus bursae slender, densely covered internally with numerous, minute, short spinules; junction with ductus seminalis near caudal 1/3. Corpus bursae membranous except for $\mathrm{V}$-shaped signum; forked arms of signum slender with minutely but coarsely serrated mesal edges (Fig. 11); arms loosely enclosed in a pair of membranous pockets (Fig. 10); walls of corpus bursae finely wrinkled.

Distribution (Fig. 12). This species occurs widely across eastern North America from Quebec, Canada to northern Florida, and west to Arkansas.

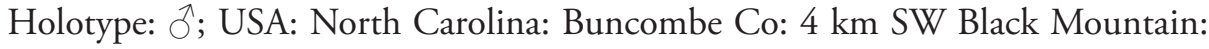
21-27 Jun 1986, W. E. Steiner, (USNM).

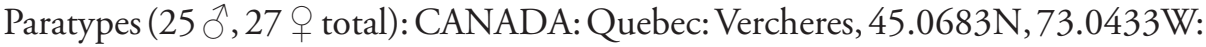
1 + 20 Jun 2005, C. Chanta, CNCLEP00028697 (CNC). USA: Arkansas: Johnson Co: 8 mi N Clarksville, T10N R23W Sect. 2: 4 तै 10-12 May 1987, R.L. Brown, (MEM). Washington Co: Fayetteville: 1 , , 17-18 May 1975, H. N. Greenbaum, at blacklight, J. B. Heppner, wing slide 28587 (USNM); 1 กै, 5-7 June 1975, H. N. Greenbaum, malaise trap, J. B. Heppner, slide 30242 (USNM); 1 + , 19-21 July 1975, H. N. Greenbaum, malaise trap, slide 20304 (USNM); 1 đ, 19/22 June 1975, H. N. Greenbaum, malaise trap (FSCA); 1 , , 17-21 July 1975, H. N. Greenbaum, malaise trap (FSCA); 1 q, 1-5 July 1975, H. N. Greenbaum, malaise trap (FSCA). DeleWARE: Newark: 1 q, 25 August 1971, D. H. Funk (USNM); 1 q, GF [Glen Farms]: 4 Jun 1974, D. F. Bray, (USNM). Florida: Escambia Co: Pensacola: 1 + 15 May 1961, Shirley Hills (USNM). MarYLAND: Allegany Co: Green Ridge St. Forest: 1 , 15 June 1992, J. Glaser (USNM). Charles Co: Myrtle Grove WMA: 1 +, 5 June 2001, J. Glaser (USNM). Dorchester Co: 3 miles E. Hurlock: 1 \%, 10 Sept. 2004, J. Glaser

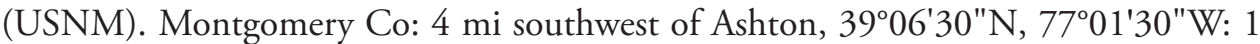
Ô, 2 Jul 2007; 1 , 24 Jul 2008, 1 +, 20 Aug 2009, G. Hevel (USNM); Laytonsville: Hoover Farm Woods: 1 §, 24 Jun 2000, D. R. Davis, DNA sample DRD-06-1340 (USNM). Plummers Island: 1 + 17 July 1999, J. Brown, head slide 33978, (USNM). Prince Georges Co: 1 , , Ft. Washington Park: 1 July 2002, J. Glaser, (USNM); Pretty- 


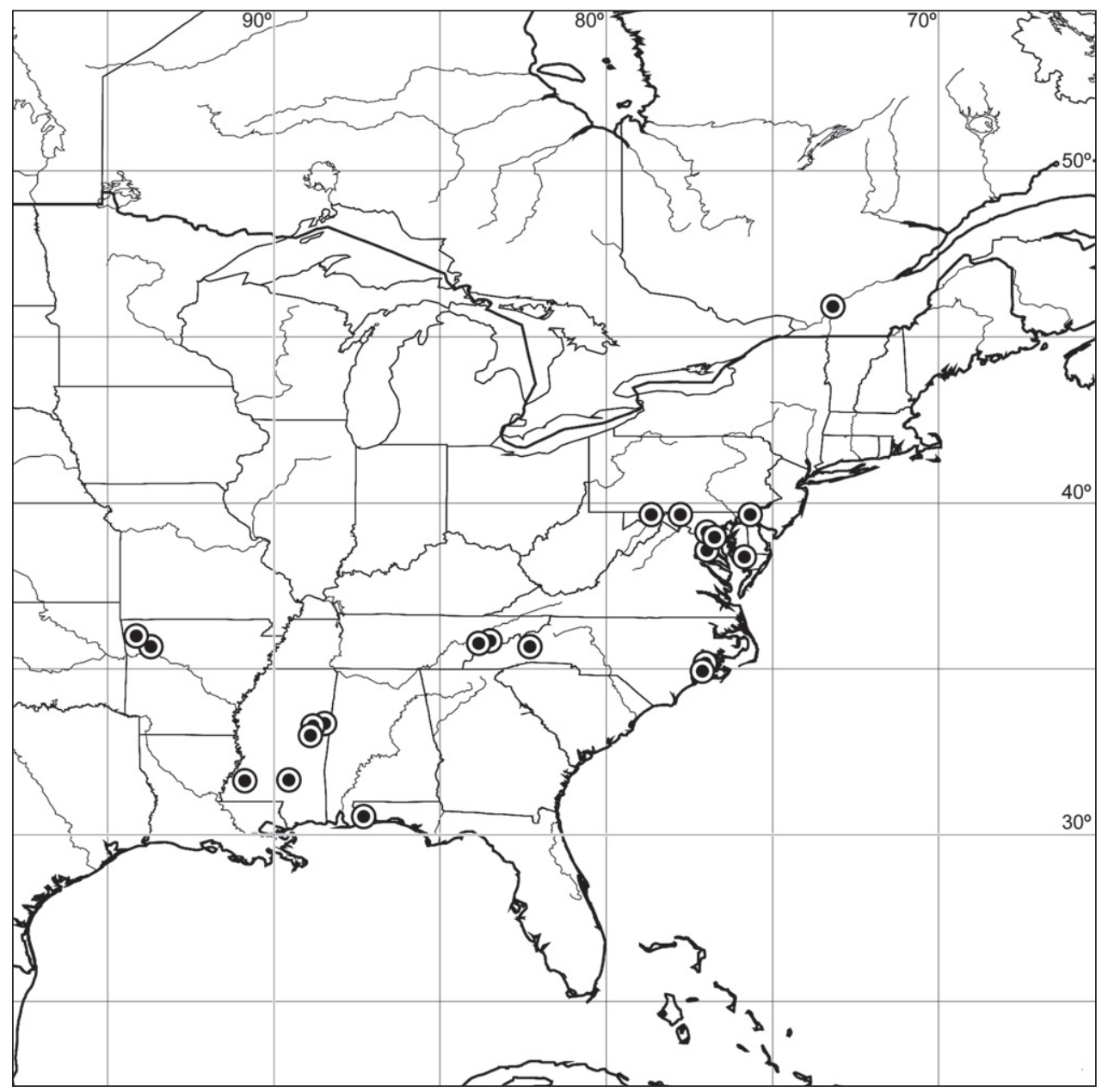

Figure 12. Distribution of Pelecystola nearctica sp. n.

boy Reservoir: 2 , 13 August 1998, J. Glaser (USNM); Piscataway Nat. Park: 1 q, 30 August 2002, J. Glaser (USNM); 1 q, 13 July 2002, J. Glaser , slide 33095 (USNM); 1 q, 8 July 2002, J. Glaser (USNM); 1 q, 8 Sept. 2002, J. Glaser (USNM). Washington Co: 2 miles E. Smithsburg: 1 ๆ, 3 July 1999, J. Glaser, (USNM). Mississippi: Franklin Co., Porter Creek, T5N R4E, Sec 8NW: 2 đ̄, 8 Apr. 1992, J. MacGown \& T. Schiefer (MEM). Lowndes Co: Crawford, T17N R16E, Sec. 34, Hickory Grove in Black Belt Prairie: 1 đ̃, 20 May 1992, R.L. Brown (MEM). Oktibbeha Co: 5 mi SW Starkville: 1 ㅇ, 13 Sept. 1984, 1 đ̃, 15 Sept. 1984, 1 ㅇ, 19 Sept. 1984, $2 \hat{\jmath}, 28$ Apr. 1986, 1 ふ઼, 30 Apr. 1987, R.L. Brown (MEM). Winston Co: Tombigbee Natl. Forest, 3310'20"N, 8903'55"W: 1 ○ 20 Apr. 1999, 1 q, 25 May 1999, R.L. Brown (MEM). North Carolina: Buncombe Co: 4 km SE Black Mountain: 1 ふ̋, 21-27 June 1986, W. E. Steiner, (USNM); Craven Co: Croatan National Forest road 1111, Brier Ck. Site: 1 đ̃, 30 Apr 1997, J. B. Sullivan, UV trap, (FSCA). Croatan National 
Forest road 3046, Gum Branch Road: 1 đૈ, 25 Apr 1996, J. B. Sullivan, UV trap, (FSCA). Croatan National Forest, Island Walk: 1 Ô, 30 Apr 1997, J. B. Sullivan, UV trap, hardwoods (FSCA). Croatan National Forest Road, 169 Little Deep Creek Road: 1 , 22 April 1999, J. Bolling Sullivan, (USNM). Jones Co: Oak Grove Air Station: 1 Oे, 12 Apr 2002, J. B. Sullivan, UV trap, Quercus, Vaccinium, xeric and Trent River bottomland (FSCA). Tennessee: Cooke Co: GSMNP, Foothills Pkwy, $2^{\text {nd }}$ pullout,

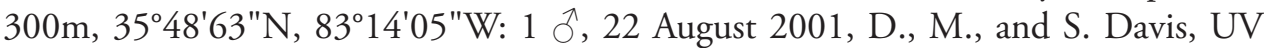
trap, (USNM); Cocke Co: Great Smoky Mountains National Park, Albright Grove

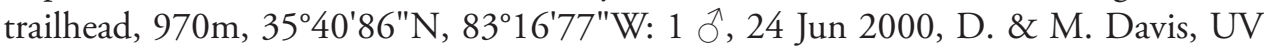
trap (USNM). Blount Co: Great Smoky Mountains National Park, 200m SW Cades Cove, ATBI house, $35^{\circ} 36^{\prime} \mathrm{N}, 83^{\circ} 50^{\prime} \mathrm{W}, 515 \mathrm{~m}: 1$ ก , 19-20 Aug. 2001, D., M. \& S. Davis, UV trap, slide 32411 (USNM). Sevier Co: Gatlinburg, Cobbly Nob, Green-

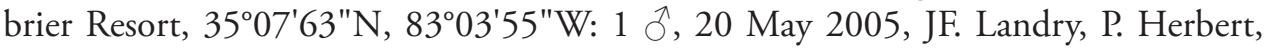
DNA-ATBI-3196 (CNC); Great Smoky Mountains National Park, University of Tennessee Field Station, 35.0739N, 83.0424W: 1 , 21 May 2005, JF. Landry, P. Herbert, DNA-ATBI-3295 (CNC).

Flight Period. Adults have been collected from April 8 to September 19 in Mississippi, with most records over much of its broad range occurring from May through August.

Etymology. The specific name is derived from the Greek neos (new) and arktos (north) in reference to the nearctic distribution of the species.

Discussion. Pelecystola nearctica is most similar in general wing pattern to the European $P$. fraudulentella Zeller 1852, currently known from only the male holotype collected nearly 160 years ago in Slovenia and a recently discovered female from Sweden (Lindeborg and Bengtsson 2008 ). The two species can be easily distinguished by male genital morphology: the valva of fraudulentella is distinct in possessing a more slender, greatly elongated saccular lobe which surpasses the apex of the cucullar lobe by nearly half its length, compared to being only slightly longer than the cucullar lobe in nearctica (Fig. 7).

The two bristles comprising the frenulum of female $P$. nearctica appear superficially to be fused as one. With slight pressure, however, these can be separated. Whether this peculiar condition of the frenulum is typical for all Pelecystola is not known.

\section{Acknowledgements}

We wish to acknowledge research assistant Patricia Gentili-Poole and illustrator Young Sohn of the Department of Entomology, Smithsonian Institution for their graphics assistance and line illustrations respectively. We thank Ole Karsholt, Universitetes Zoologisk Museum, Copenhagen, Denmark and Gaden Robinson of the Natural History Museum, London, UK for bringing the little known genus Pelecystola to our attention, which assisted in determining the generic placement of the new North American species. We thank John Glaser, Berkeley Springs, West Virginia, 
for the donation of a comprehensive collection of eastern North American Lepidoptera to the Smithsonian Institution, which included specimens of Pelecystola nearctica. Richard Brown, Mississippi Entomological Museum, Mississippi State, MS, John Heppner, Florida State Collection of Arthropods, Gainesville, FL, and JeanFrançoise Landry, Agriculture and Agri-Food Canada/Agriculture, Ottawa, Canada provided material and specimen data. Makoto Sakai, Hunan University, China and Toshiya Hirowatari, Osaka Prefecture University, Osaka, Japan provided descriptions and illustrations of the Asian species, Pelecystola strigosa. We are grateful to Keith Langdon, Great Smokey Mountains National Park (GSMNP), for assistance with collecting permits, and Jeanie Hilten, Discover Life in America (DLIA) for logistic support of field work within GSMNP. DLIA and the Smithsonian Institution's Biodiversity Programs also provided funding for field work in the Great Smokey Mountains National Park during 2000 and 2001. Thanks also to David L. Wagner, University of Connecticut, Storrs, CT and Brian Scholtens, College of Charleston, Charleston, SC, for organizing and inviting us to participate in the Lepidoptera BioBlitzes held during 2000, 2002, and 2004 in GSMNP. Support for gene sequencing was provided by the U.S. National Science Foundation's Assembling the Tree of Life program, award numbers 0531626 and 0531769.

Finally we acknowledge the cooperation of the staff and institutions listed below and list their acronyms as used in this study:

BMNH The Natural History Museum (formerly the British Museum (Natural History)), London, United Kingdom.

CNC Canadian National Collections of Insects, Arachnids and Nematodes, Agriculture and Agri- Food Canada, Ottawa, Canada.

FSCA Florida State Collection of Arthropods, Gainesville, Florida, USA.

MEM Mississippi State Entomological Museum, Mississippi State, Mississippi, USA.

USNM Collections of the former United States National Museum, now deposited in the National Museum of Natural History, Smithsonian Institution, Washington, D.C., USA.

\section{References}

Davis SR, Davis DR (2009) Neotropical Tineidae VIII: Falsivalva, a new genus of Tineidae from austral South America with extreme modification of the male postabdominal terga (Lepidoptera: Tineoidea). Proceedings of the Entomological Society of Washington, 111(2): 378-392.

Gozmány LA, Vári L (1973) The Tineidae of the Ethiopian Region. Transvaal Museum, Memoir 18: i-vi, 1-238.

Lindeborg M, Bengtsson BÅ (2008) On the remarkable find of Pelecystola fraudulentella (Zeller, 1852 ) in Sweden (Lepidoptera: Tineidae). [Om det sensationella fyndet av Pelecystola fraudulentella (Zeller 1852) (Lepidoptera: Tineidae)]. Entomologisk Tidskrift 129: 73-79. 
Meyrick E (1920) Voyage de Ch. Allauaud et R. Jeannel en Afrrique Oriental, Resultats Scientifiques, Insectes Lépidoptères 2: 35-120.

Meyrick E (1937) Exotic Microlepidoptera, 5 (pts. 3-5): 65-96.

Meyrick E (1938) Tortricina and Tineina from the National Albert Park. Institut des Parcs Nationaux du Congo Belge 14: 3-28.

Robinson GS (2008) Global taxonomic database of Tineidae (Lepidoptera) (v. 8.0). http:// www.nhm.ac.uk/entomology/tineidae/index.html

Robinson GS, Tuck KR (1996) A revisionary checklist of the Tineidae (Lepidoptera) of the Oriental Region. Occasional Papers on Systematic Entomolgy 9: 1-29.

Sakai M (2002) Systematic study of the family Tineidae of Japan (Insecta: Lepidoptera). Unpublished PhD Thesis. Kyushu University, Japan.

Zeller PC (1852) Die Schaben mit laugen Kiefertastern. Linnaea Entomologica 6: 81-197. 